\title{
Design of Acceleration's Monitoring System by Computer with Bluetooth Communication to Determine Intensity
}

\author{
Ijabatul Khoirunnisa*, Frida Agung Rakhmadi**, Nugroho Budi Wibowo*** \\ Physics Department, Faculty of Science and Technology, UIN Sunan Kalijaga Yogyakarta \\ Jl. Marsda Adisucipto No 1 Yogyakarta 55281, Indonesia. Tel. +62-274-540971, Fax. +62-274-519739. \\ Email: ijabatulk@gmail.com*, agungfrida@yahoo.co.id**, nugrohobudiwibowo@gmail.com***
}

\begin{abstract}
Khoirunnisa I, Rakhmadi F A, Wibowo N B. 2017. Design of Acceleration's Monitoring System by Computer with Bluetooth Communication to Determine Intensity. Proc Internat Conf Sci Engin 1: 193-195. Indonesia lies on the junction of three large plates, resulting in frequent occurrence of earthquakes. This research is trying to design a building acceleration monitoring system which the purpose of this research was to create and characterize the acquisition system, to create and test the building acceleration monitoring system by computer with bluetooth communication. This research was conducted in five phases: making the data acquisition system, characterizing of data acquisition system, making monitoring system, data sampling of monitoring system, and data analyzing of monitoring system. The result of this research showed that transfer function and correlation coefficient of data acquisition on each axis was: $y_{x}=16,722 a_{0 x}+0 r_{x}=1 ; y_{y}=16,722 a_{0 y}+0 r_{y}=1$; and $y_{z}=16,722 a_{0 z}+0 r_{z}=1$. Sensitivity of the acquisition system on each axis was $16,722 \mathrm{bit} / \mathrm{gal}$. Acceleration data of monitoring system has range $-0,17944$ gal to 0,119628 gal which intensity 0 MMI. Accuracy of earthquake's monitoring system on $\mathrm{x}$ axis was $97,204 \%$, y axis was $97,374 \%$, and $\mathrm{z}$ axis was $97,210 \%$.
\end{abstract}

Keywords: Acceleration, Intensity, Acceleration's Monitoring

\section{INTRODUCTION}

Indonesia lies on the junction of three large plates, which Indo-Australian, Philippines, and Eurasia. The movement of plates causes the energy to accumulate, if the rock layers are unable to resist it will release energy that causes fault or deformation of the earth's crust and there is a tectonic earthquake. Earthquake becomes one of the causes of the seismic in an area. Seismic of the ground sends the seismic to the building standing on it, resulted in acceleration of building. The acceleration have vertical or horizontal motion directions. Vertical acceleration are generally less harmful because it have same direction with gravity. Horizontal direction causes the building feel as though swing. Frequent occurrence of earthquakes in Indonesia, resulting in earthquake disaster which take casualties. Manufacture of telemetry-based earthquake monitoring system can minimize the risk of building disaster. Telemetry-based earthquake monitoring system can provide information in the form of data acceleration and the intensity in realtime. This device requires sensors with high distribution, this is an accelerometer sensor with detection area on the axis of $\mathrm{x}, \mathrm{y}$, and $\mathrm{z}$ with the wireless transmission. Accelerometer sensor MMA7455L and bluetooth communication applicable to this device.

The purpose of this research was to create and characterize the acquisition system, to create and test the building acceleration monitoring system by computer with bluetooth communication. The design of acceleration monitoring system and intensity gen up acceleration and intensity. Acceleration data is a means of information to estimate and minimize the impact caused by the earthquake. From the value of acceleration will be obtained intensity in the MMI scale, so it can be known the risk of building disaster causes of earthquake. Intensity is a description of the strength of earthquakes and their effects on the earth's surface, such as buildings, topography and so forth, which are generally called macro effects. Thus, people know what they must do to save themselves from earthquake disaster. In addition, it can be used as an evaluation material in the manufacture of earthquake resistant buildings in the future.

\section{MATERIALS AND METHODS}

\section{Study Area}

Acquisition system and monitoring system conducted on station of Geophysics in BMKG. Performed at station of Geophysics in BMKG because there are device that have been standard as a reference. In addition, in this station have a little disturbance of acceleration.

\section{Procedures \\ - Design of monitoring system}

The monitoring system made of two stages, hardware manufacture and software manufacture. Hardware manufacture includes the design of monitoring systems and circuit schemes. While the software includes making the program for data processing and interface on the computer. Materials for producing monitoring system are accelerometer sensor MMA7455L as an acceleration detector, Raspberry Pi 3 Model B as a microcontroller, and bluetooth as communication data transmission from sensor to computer. This monitoring system can display the graph of acceleration, value of 
acceleration, and intensity on the computer. The monitoring system diagram is shown on Figure 1.

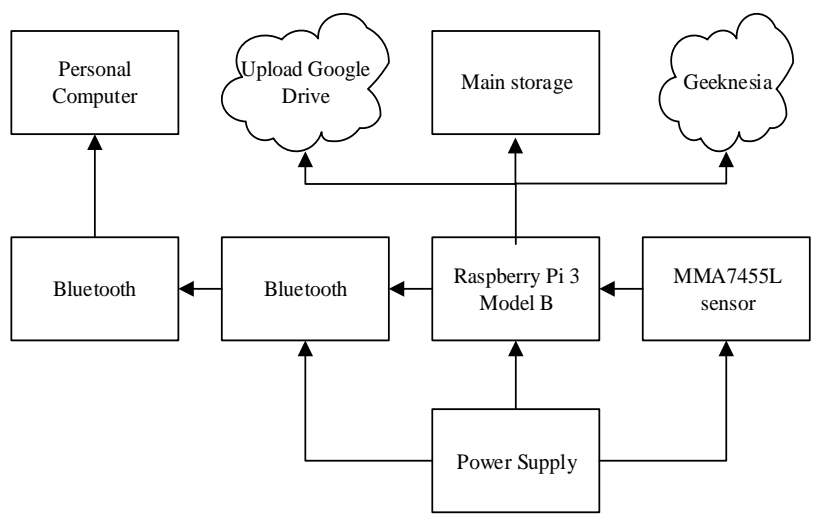

Figure 1. Diagram of monitoring system.

\section{- Implementation}

Implementation is divided into two the implementation of hardware and software. The hardware implementation can be seen in Figure 2, while the software implementation is shown in Figure 3.

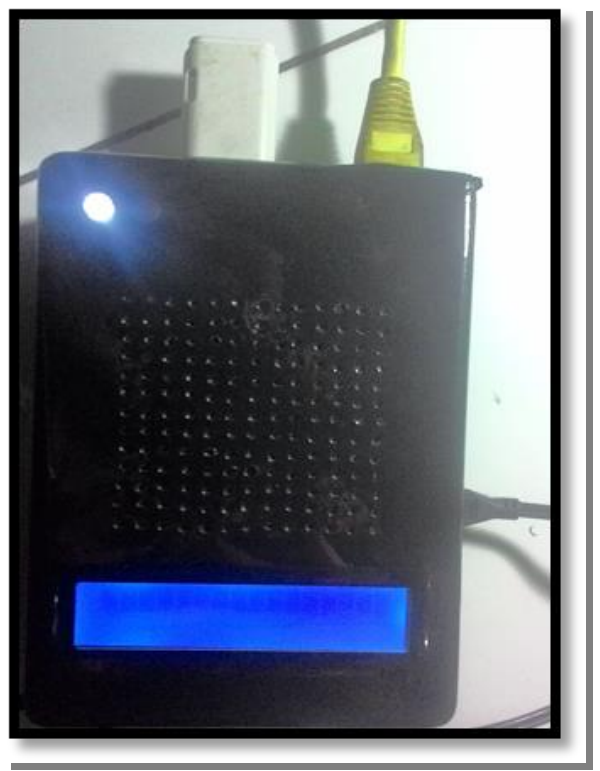

Figure 2. Hardware implementation

Table 1. Result of acceleration monitoring system

\begin{tabular}{lccccc}
\hline \multirow{2}{*}{ Information } & \multicolumn{3}{c}{ Device Data (gal) } & \multicolumn{2}{c}{ Intensitymeter Data (gal) } \\
\cline { 2 - 5 } & $\mathbf{x}$ & $\mathbf{y}$ & $\mathbf{z}$ & $\mathbf{x}$ & 0,1196 \\
\hline $\mathrm{a}_{\max }$ & 0,059814 & 0,119628 & 0,119628 & 0,0598 & $-0,1196$ \\
$\mathrm{a}_{\min }$ & $-0,179442$ & $-0,119628$ & $-0,119628$ & $-0,1794$ & $-0,1196$ \\
$\mathrm{a} 0$ & & 0,119628 & & 0,1196 \\
MMI & & 0 & & 0 \\
\hline
\end{tabular}

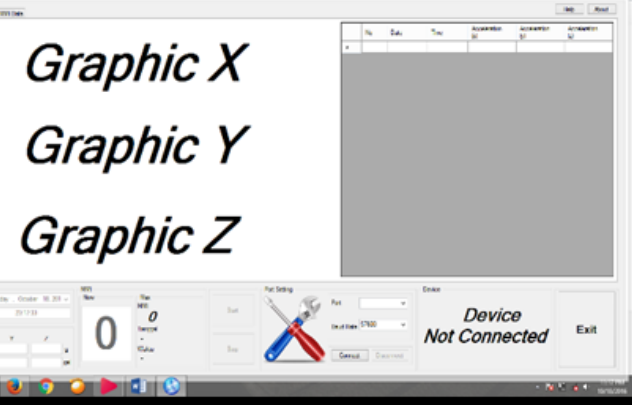

Figure 3. Software implementation

\section{Data Analysis}

- Design of Monitoring System

Design of monitoring system are shown in Figures 4. Result of monitoring system showed on monitor, LCD, LED, and buzzer. Monitor displayed the acceleration data in 1 second, intensity, time, acceleration data record, and graph of the acceleration. LCD displayed value of acceleration, intensity, date, and time. Buzzer and red LED are active when MMI> 3, green LED is active when device is ready to receive data, and white LED indicates that device getting electrical power. Data transmission from device to monitor using bluetooth communication.

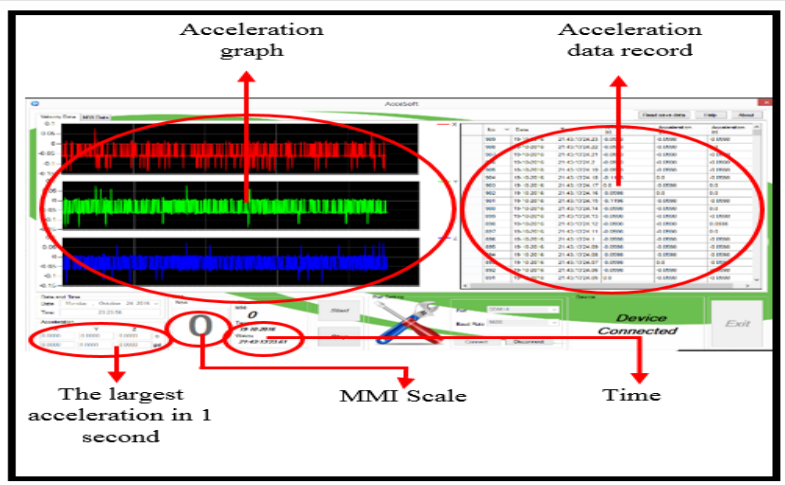

Figure 4. Display on the device of monitoring system.

- Acceleration Monitoring System

Result of acceleration monitoring system showed in table 1. There are acceleration and intensity in MMI scale. 
The data acquisition system has been made by the characteristics of transfer function and correlation coefficient on each axis was $y_{x}=16,722 a_{0 x}+0 r_{x}=1$; $y_{y}=16,722 a_{0 y}+0 \quad r_{y}=1 ;$ and $y_{z}=16,722 a_{0 z}+0 r_{z}=1$; sensitivity of the acquisition system on each axis was 16,722 bit / gal.

\section{RESULTS AND DISCUSSION}

Monitoring is demonstrated through LED indicators and monitors on the computer. The white LED light indicates that there is a power supply coming into the circuit. The green LED light indicates the recording device is ready to receive input. The computer is used to display data, by sending data from the vibration recorder to the computer using bluetooth communication. Red LED, buzzer, and LCD lamps are used as an indicator in case of vibration with intensity scale of more than III MMI. In case of vibration with intensity scale of more than III MMI, the red LED light is on, active buzzer, and on LCD screen will show the greatest building acceleration value of $\mathrm{x}, \mathrm{y}$, and $\mathrm{z}$ axis and intensity scale, while if the intensity scale is less of III MMI, then the red LED light is off and buzzer is off.

The microprocessor on the accelerometer will read the output of the sensor which is then converted to the acceleration of the building with the gal unit. The converted data is then processed using equation $I_{0}=3 \log a_{0}+1,5$ to obtain the scale of the damage intensity of the building in MMI through the scripts inserted into the microprocessor. The processing by the microprocessor is then displayed on the LCD screen, stored on the main storage media in the form of flash 16 $\mathrm{GB}$, archived for further upload to google drive, sent to geeknesia, and sent to bluetooth transmitter to bluetooth receiver. The data on the bluetooth receiver is then sent to the computer and displayed on the monitor screen and stored as a database.

Result of this research obtained intensity scale is 0 MMI with range of acceleration from -0.179442 gal to 0.119628 gal. Negative value is used as a direction of the building movement. The MMA7455L is sensor acceleration based on the change of capacitance. Structure of capacitor used two plates which separated by dielectric of polysilicon. The MMA7455L sensor have working principle that seismic which received by sensor causes polysilicon will flow along the $\mathrm{x}, \mathrm{y}$, and $\mathrm{z}$ axes, depending on direction of seismic. The number of deflections of each axis is measured and translated by the sensor as data acceleration in electrical quantities. This data converted by sensor into digital data and used as the output of the MMA7455L sensor.

The building always have acceleration with a very small value. This value indicates that building always have movement, although no eye has seen. Movement of building caused by various activity, such as traffic, human activities, plates activities and so forth.
Vibrations that have high frequencies and amplitudes are often referred as earthquakes. Earthquakes can be sourced from various events, such as the movement of plates and human activities. Local effects on earthquakes such as the intensity of earth shaking during the earthquake, damage of building structures, and many of the people was dead. The intensity of ground shaking during the earthquake is affected by rock conditions and soil conditions. Soft of sedimentary and soil will gave rein to seismic during earthquake. Power of seismic causes damage of building as compared of building which stand on hard of sedimentary and soil. Result of testing acceleration monitoring system have accuracy for $\mathrm{x}$ axis 97,204\%, $\mathrm{y}$ axis $97,374 \%$, and $\mathrm{z}$ axis $97,210 \%$.

\section{CONCLUSIONS}

The result of this research showed that transfer function and correlation coefficient of data acquisition on each axis was: $y_{x}=16,722 a_{0 x}+0 \quad r_{x}=1 ; y_{y}=16,722 a_{0 y}+0$ $r_{y}=1$; and $y_{z}=16,722 a_{0 z}+0 r_{z}=1$. Sensitivity of the acquisition system on each axis was 16,722 bit/gal. Acceleration data of monitoring system has range 0,17944 gal to 0,119628 gal which intensity 0 MMI. Accuracy of earthquake's monitoring system on $\mathrm{x}$ axis was $97,204 \%$, $y$ axis was $97,374 \%$, and $\mathrm{z}$ axis was $97,210 \%$.

\section{ACKNOWLEDGEMENTS}

The authors would thanks to geophysics station in Indonesian Agency for Meteorological, Climatological and Geophysics for supporting this research.

\section{REFERENCES}

Bath, M. 1979. Introduction to Seismology. Birkhäuser Verlag, Stuttgart.

Fraden, J. 2004. Handbook of Modern Sensors. Springer-Verlag, New York

Lay, T dan Wallace, T. C. 1995. Modem Global Seismology. Academic Press, USA.

Lueth, K. S. 2015. IoT basics: Getting started with the Internet of Things. IoT Analytics, Jerman.

McManus, S. dan Mike C. 2013. Raspberry Pi For Dummies. John Wiley \& Son, Canada.

Miller, M. 2001. Discovering Bluetooth. Sybex Inc, Alameda.

Morris, A. S. 2001. Measurement and Instrumentation Principles. Butterworth-Heinemann, England.

Murty, C. V. R. 2005. Learning Earthquake Design and Construction. Building Materials and Technology Promotion Council, New Delhi

Rakhmadi, I. dan Basuki, P. 2013. Purwarupa Sistem Pemantau Getaran pada Bangunan Bertingkat Dua Menggunakan Sensor Akselerometer. IJEIS, Vol. 3 No. 2 October 2013: 197-206.

Santana, J. et al. 2012. A3-axis accelerometer and strain sensor system for building integrity monitoring. Science Direct, Sensor and Actuator A: Physical: 141-147. 
THIS PAGE INTENTIONALLY LEFT BLANK 